\title{
Integrity and Learning: Enhancing Workability and Student Performance Outcomes
}

\author{
Steven C. Isberg, Ph.D \\ University of Baltimore
}

Tomas Thundiyil

Texas A\&M University

\section{Robert Owen \\ Thunderbird School of Business}

\author{
Contact: \\ sisberg@ubalt.edu \\ --Draft: Comments Welcomed-- \\ 18 September 2012
}

\section{Integrity and Performance in Higher Education}

Is it possible to define the practice of integrity and measure its impact on workability, teaching, and learning outcomes? Is the practice of integrity constrained by faculty and/or student workload responsibilities? Can improving the practice of integrity put today's "academically adrift" students and their professors back on course to maximize the opportunities and outcomes for performance in the classroom?

Researcher George Kuh describes the current environment in higher education as governed by a "disengagement contract" in which professors and students implicitly agree to minimize each other's workloads in exchange for rewarding sub-standard performance with inflated grades and favorable teaching evaluations. According to Kuh, the compact goes something like this:

"I'll leave you alone if you leave me alone. That is, I won't make you work too hard (read a lot, write a lot), so that I won't have to grade as many papers, or explain why you are not performing well. The existence of this bargain is suggested by the fact that at a relatively low level of effort, many students get decent grades---B's or better. There seems to be a breakdown of shared responsibility for learning-on the part of faculty members who allow students to get by with far less than maximum effort, and on the part of students, who are not taking full advantage of the resources institutions provide."

While college level courses are represented as requiring sufficient work to earn a stated amount of credit hours, students are earning the same grades while devoting substantially less time, and learning less, than their predecessors. The end 
result is students who are unprepared to face the challenges with which they will be confronted in the workplace, as citizens, and in their private and personal lives.

The misrepresentation of the intrinsic value of college courses and the resulting student performance is, in essence, evidence of a lack of integrity in the relationship between professors and students. Each group is implicitly dishonoring its "word," in the sense that what they lead others to believe about the value of a college course is a substantial overstatement of the actual outcome. Since integrity can be defined by the degree to which one honors his word (see below), what we see here is a fundamental breakdown of integrity in the educational process.

As identified by Erhard, Jensen, and Zaffron (2010) a loss of integrity will inevitably lead to a deterioration of workability, and thus, performance. When individuals lack integrity, the opportunity for performance, first on the part of the individual and then the organization in which they operate, is compromised and therefore reduced. The authors define this concept as the Ontological Law of Integrity, which states:

To the degree that integrity is diminished, the opportunity for performance (the opportunity set) is diminished. ${ }^{1}$

\section{Integrity and Workability}

What, however, do these authors mean when they refer to the concept integrity. In their model, integrity is defined as a positive phenomenon, and is differentiated from the normative concepts of morality and ethics. Integrity, as the authors define it, is a state of existence, and therefore ontological in nature. Their definition of integrity is first based on the Webster's New World Dictionary definition of the word itself, which is:

a. the quality or state of being complete; unbroken condition; wholeness; entirety;

b. the quality or state of being unimpaired; perfect condition; soundness;

The authors then go further to identify and define that integrity for an individual is based upon the completeness, unbroken-ness, wholeness, and perfect condition of his or her word, as follows:

(We) define integrity for a person as: honoring one's word (as one's word is defined in the preceding sections). Notice that we did not say that integrity is a matter of keeping one's word; we said that integrity is honoring one's word.

In this new model of integrity we define honoring your word as:

${ }^{1}$ Erhard, Jensen, and Zaffron (2010), page 7 
1. Keeping your word (and on time). And, whenever you will not be keeping your word:

2. Just as soon as you become aware that you will not be keeping your word (including not keeping your word on time) saying to everyone impacted;

a. that you will not be keeping your word, and,

b. that you will keep that word in the future, and by when, or that you won't be keeping that word at all, and,

c. what you will do to deal with the impact on others of the failure to keep your word (or to keep it on time). ${ }^{2}$

The authors also state that what constitutes one's word requires a clear definition, which is provided as:

1. What You Said: Whatever you have said you will do or will not do, and in the case of do, by when you said you would do it.

a. Note A - Requests Of You Become Your Word Unless You Have Timely Responded To Them: When you have received a request, you may accept, decline, make a counter offer, or promise to respond at some specific later time. If you do not timely respond to a request with a decline, counter offer, or promise to respond at some specific later time (which promise you timely honor), you have in effect accepted (given your word to) that request.

b. Note B - In Contrast, Your Requests Of Others Do Not For You Become Their Word When They Have Not Responded In A Timely Fashion: The efficacy of this asymmetry is explained below in Section D, Clarification of One's Word-3, Note.

2. What You Know: Whatever you know to do or know not to do, and in the case of do, doing it as you know it is meant to be done and doing it on time, unless you have explicitly said to the contrary.

3. What Is Expected: Whatever you are expected to do or not do (even when not explicitly expressed), and in the case of do, doing it on time, unless you have explicitly said to the contrary.

a. Note - In Contrast, Your Expectations Of Others Are Not For You The Word Of Others: What you expect of others and have not explicitly expressed to them is not part of their word as defined in this new model. Only those expectations you have of others that you have made clear to them by a request is part of their word (unless they decline or counter- propose your request).

4. What You Say Is So: Whenever you have given your word to others as to the existence of some thing or some state of the world, your word includes being willing to be held accountable that the others would

2 Erhard, et. Al (2010), page 16 
find your evidence for what you have asserted also makes what you have asserted valid for themselves.

5. What You Stand For: What you stand for is fundamental to who you are for yourself and who you are for others. What you stand for is a declaration constituted by

a. who you hold yourself to be for yourself as that for which you can be counted on from yourself (whether specifically articulated by you or not), and

b. who you hold yourself out to be for others as that for which you can be counted on by others (or have allowed others to believe as that for which you can be counted on). The importance of this aspect of one's word in the matter of integrity is pointed to by Cox et al in the Stanford

Encyclopedia of Philosophy who devote an entire section to "Integrity as Standing for Something".

6. Moral, Ethical And Legal Standards: The social moral standards, the group ethical standards and the governmental legal standards of right and wrong, good and bad behavior, in the society, groups and state in which one enjoys the benefits of membership are also part of one's word (what one is expected to do) unless a) one has explicitly and publicly expressed an intention to not keep one or more of these standards, and b) one is willing to bear the costs of refusing to conform to these standards (the rules of the game one is in). ${ }^{3}$

The fact that this definition of integrity is a positive as opposed to a normative phenomenon now opens the opportunity for restoring and measuring the impact of integrity on the classroom experience. This means that teachers establish conditions and honor their word to enable students to fulfill the "promise" of a course learning experience. For a student, integrity can be measured as the degree to which he or she honors his or her word regarding the conditions for maximizing performance in a class. The first step is to articulate the conditions to which students are giving their word by enrolling in the class and the second is to create and implement a grading rubric to determine whether this has been accomplished.

\section{Restoring Integrity and Workability: Identifying Conditions for Realizing the "Promise" of a Course}

Instructors can articulate the promise of a course in the form of a set of learning objectives. For example, "After completing this course the student will be able to calculate a corporate cash flow and use a weighted average cost of capital to determine the value of that cash flow." In order for this and other learning objectives to be accomplished, a class environment needs to be created in which instructors are enabled to effectively teach and students to effectively learn.

3 Erhard, et. al., (2010); page 11 
Integrity is essential to this environment because, as stated earlier, integrity affects workability.

Workability in the classroom is enhanced by integrity at a number of levels. First, when individual students honor their word to themselves, they maximize their opportunity for success. Opportunities for success are further increased when students honor their word to each other and to the instructor, and when the instructor honors his or her word to the students. The first steps in this process are to clearly articulate the promise of the course and the conditions for achieving the promise of the course.

The concepts of integrity, workability, and achieving the promise of the course are drawn closely together in the work of Erhard, Jensen, Zaffron and Granger in their approach to teaching leadership. Prior to engaging in their course, Being $\boldsymbol{a}$ Leader and the Effective Exercise of Leadership: An Ontological Model, students are provided with a clear articulation of the promise of that course; that by honoring their word to agree to be in integrity with the course conditions, they will be able to exercise leadership as their natural form of self-expression. The authors then go on to rigorously define and articulate what it means to honor your word regarding the conditions for realizing the course promise. Enrollment in the class implies that students have, in fact, given their word to do so, and are willing to be accountable for honoring that word. The key first step, therefore, in grading this notion of integrity is to clearly articulate the promise of the course and the conditions for realizing that promise.

\section{Finance 332: Financial Modeling and Communication}

Financial Modeling and Communication is an undergraduate course for finance majors. The main objective of the course is to enable the students to apply a variety of financial analysis tools and models to problem solving situations and communicate their findings in written form. The course is based on case analysis. Class sessions involve presentation and review of advanced applications of financial tools and models, and discussions of case material. The promise of the course is articulated to the students on the first day of class as follows:

\section{Finance 332: The Course Promise}

There are three main objectives (AKA: "The Promise") of Finance 332. These statements represent the future into which you are living as a result of your participation in this course.

1. Students have the skills needed to conduct critical analysis using different financial analytical tools. This includes problem finding and problem solving.

2. Students have the skills needed to effectively communicate in written form (e.g., business memoranda, reports, and exhibit documentation) using electronic media (word processing, spreadsheets, e-mail, internet utilities).

3. Students conduct business and personal affairs with integrity 
The students are then provided an overview of the conditions necessary for them to realize the promise. These are presented as follows:

\section{Finance 332: Conditions for Realizing the Promise: Analytical}

Students develop critical thinking, analytical, and problem finding and solving skills by way of participating in lectures and class exercises, self-testing, spreadsheet work, and case analysis.

1. Lectures and class exercises: Students prepare for and participate in lectures by completing assigned reading prior to the scheduled lecture and engaging in discussion during class.

2. Self-testing: Students complete five self-test exercises outside of class, submitting results on time.

3. Spreadsheets: Students complete five spreadsheet analyses as outside assignments, one as a final project, and a variety of others as class exercises, submitting results on time.

4. Case Analysis:

a. Students prepare and participate in a variety of problem solving and case exercises to be discussed in class

b. Students conduct analysis on at least five case assignments to be completed outside of class (see Communication, below).

\section{Finance 332: Conditions for Realizing the Promise: Communication}

Students realize the communication promise by completing and submitting written documentation of their analysis of five cases and a comprehensive final analysis project

1. The first five written case analysis consist of one-page business memoranda and accompanying exhibit documentation

2. The final project consists of a three-to-four page written analysis and supporting exhibit documentation

3. Students submit written and exhibit documents electronically, in the proper format, and on time.

\section{Finance 332: Conditions for Realizing the Promise: Integrity}

Students conduct their business and personal affairs relating to this class with integrity by honoring their word to fulfill the conditions for realizing the promise of the course.

1. What it means to both keep and honor your word will be carefully articulated on the first day of class.

2. In order to realize the promise of this course, you must give your word, to yourself, your instructor, and your classmates, to rigorously pursue completion of all work assignments required by this course. 
3. If you have difficulty with the material or in regard to honoring your word, you give your word to seek assistance on a timely basis.

4. Giving your word includes the commitment to complete this work on time

5. Choosing to remain in the class will mean that students agree to act in integrity, honoring their word.

\section{Grading Structure}

The grading structure for the course was somewhat different from most others. While students completed a series of exams and written assignments during the semester, the only grades that counted toward the course grade were those on the final exam and final course project.

Exams administered during the semester were given as self-test opportunities. Students were provided with exams that were made available at a certain time by way of an online system. Students were advised to administer these exams to themselves under regular testing conditions that included a fixed time period and no outside notes. Students were then asked to post their results back to an online assignment folder. After the due date for posting results, the answers to the self-tests were released and students were asked to check their own work. Class time was then reserved during which students could ask questions about the selftest solutions.

Written assignments administered during the semester were rigorously graded for writing, analytical, and exhibit presentation quality. Students were given extensive feedback regarding opportunities to improve their work. After the first two assignments, students were informed as to what letter grade would apply to their papers if such grades were being assigned. The purpose of this process was to allow the students to create opportunities to improve and benefit from the feedback, rewarding them for the grade that they had earned as a result of that improvement as opposed to a grade based on an average of where they were at the beginning and end of the semester.

Students were asked to submit their papers by 7:00 am on each designated due date, and were promised that their work would be evaluated and returned within 24-48 hours. This demonstrated the importance of the instructor keeping his word in order to enable them to realize the promise of the course. In many cases, the instructor invited the student to schedule an office conference to review his or her work, and/or to seek assistance from the writing counselors provided by the Achievement and Learning Center on campus.

The final exam was cumulative and structured in similar fashion to the five self-tests administered during the semester. The final course project was also cumulative in nature. It involved a complex spreadsheet analysis encompassing all of the techniques developed in the class over the semester (ratio analysis, pro forma 
forecasting, weighted average cost of capital and cash flow calculation, and valuation).

\section{Integrity Grading Rubric}

The rubric for grading integrity is provided as Exhibit 1 . As can be seen, there were four categories of grading: class attendance, (0-5 points); assignment submission ( $0-10$ points); self-test completion (0-5 points); and seeking assistance (0-5 points).

\section{Attendance}

Students earned perfect attendance scores by attending all class sessions, arriving both on time and prepared. Preparation was monitored by the periodic collection of discussion notes and tables that students were asked to complete before coming to class. As can be seen in the rubric, the definition of honoring one's word was used in developing the scoring system. If a student was unable to attend a class, he or she had given his or her word to let the professor know as soon as he or she became aware of the forthcoming absence, or as soon as possible in the case of an unforeseen emergency. More importantly, the student was responsible for providing a plan to make up for any deficiencies caused by either arriving late or missing the entire class.

\section{Assignment Submission}

As mentioned earlier, the written assignments did not receive letter or number grades. As per the integrity rubric, the assignments had to be submitted on time and in proper format. Proper format included one MS Word file containing the written document, and one MS Excel file containing all of the spreadsheet exhibits. Formatting within the written and spreadsheet work was also evaluated and applied to the assignment submission score.

\section{Self-test completion}

Students were asked to post self-test results to their online assignment folder by a certain time. For each self-test, about $20 \%$ of the submissions were checked to determine whether the work had been properly completed, so every student was checked at least once over the course of the semester. Otherwise, the students earned credit for posting on time.

\section{Seeking assistance}

As mentioned earlier, students were encouraged to seek assistance in a variety of forms over the course of the semester. In many cases, the instructor invited them to seek assistance on analytical and spreadsheet problems by 
scheduling office conferences. In other cases, the instructor encouraged students to seek assistance of the writing counselors in the Achievement and Learning Center. A referral form on which the instructor indicated the areas in need of work and allowed the student to document the session with the counselor aided this process. In many other cases, students initiated the process of seeking assistance on their own.

\section{Analysis of Integrity and Its Relation to Performance}

The integrity initiative was implemented in two sections of the course meeting in the fall semester of 2010. One section of the class met twice per week for 80 minutes during the day. The second section met once per week for 150 minutes per week at night. The classes were composed of junior and senior level students majoring in either finance or real estate and economic development. While many of these students carry full-time course loads (12.0 credits or more), a significant majority of them also work more than 20 hours per week on jobs outside of school. Several work as many as 40-50 hours per week on these jobs. As can be seen in Exhibit 1, there were 22 and 31 students in the day and night sections respectively. The day students take an average of about 2.0 more credit hours than the evening students (14.68 as compared to 12.65). This is primarily due to the fact that the evening students tend to work more hours of employment. The average GPA for the daytime students was also greater than that for the evening students ( 3.27 as compared to 3.04). This is consistent with assessment results in other classes, where night students, who work a greater number of hours outside of school, tend to earn lower GPA's, on average, as compared to the daytime students.

Exhibit 1

Enrollment and Averages for Course Integrity, Exam and Assignment Grades, GPA, and Credit Hour Averages for Finance 332: Fall 2010 (Day Section) and Spring 2011 (Night Section)

\begin{tabular}{|l|c|c|c|c|c|c|c|}
\hline Class Section & $\begin{array}{c}\text { Number } \\
\text { Enrolled }\end{array}$ & $\begin{array}{c}\text { Credit } \\
\text { Hours } \\
\text { Enrolled }\end{array}$ & $\begin{array}{c}\text { Entering } \\
\text { GPA }\end{array}$ & $\begin{array}{c}\text { Integrity } \\
\text { (Max 25) }\end{array}$ & $\begin{array}{c}\text { Final Exam } \\
\text { (Max 100) }\end{array}$ & $\begin{array}{c}\text { Final } \\
\text { Project } \\
\text { (Max 15) }\end{array}$ & $\begin{array}{c}\text { Points } \\
\text { (Max } \\
\text { 115) }\end{array}$ \\
\hline Night & 31 & 12.65 & 3.04 & 16.97 & 46.49 & 10.65 & 57.15 \\
\hline Day & 22 & 14.68 & 3.27 & 21.05 & 69.65 & 9.99 & 79.64 \\
\hline Total & 53 & 13.49 & 3.14 & 18.66 & 56.10 & 10.38 & 66.48 \\
\hline
\end{tabular}

There were some significant differences in the performance of students between the two sections of the course, with the daytime students outperforming the night students across the board. As can also be seen in Exhibit 1, the average scores for Integrity were 21.05 for the day and 16.97 for the evening students. There was also a significant difference on the final exam score, with the daytime students scoring an average of 23 points higher than the night students. The scores on the final project were closer, yet the day students still outperformed the night students. The maximum point total reflects the sum of the final exam and project scores. 
An analysis of the correlation of these different variables both shows the differences between the day and night students, but also supports the hypothesis that higher performance is correlated with greater integrity scores regardless of the class in which students were enrolled. As can be seen in Exhibit 2, there were high correlation coefficients between a student's integrity score and performance on the final exam and project. It is also apparent that there exists a relatively high correlation between a student's integrity score and his or her incoming GPA. This raises the question of whether one is simply a proxy for the other. It would make sense that students who tend to act with greater integrity earn higher GPA's. In this case, the GPA's were earned prior to the student's introduction to the ontological model of integrity. In order to filter out these effects, a regression analysis was conducted for each individual class and for the sample as a whole.

\begin{tabular}{|c|c|c|c|c|c|c|c|}
\hline \multicolumn{8}{|c|}{ Exhibit 2} \\
\hline \multicolumn{8}{|c|}{ Correlation Matrix } \\
\hline Variable & $\begin{array}{c}\text { Night } \\
\text { Student }\end{array}$ & Integrity & Final Exam & Final Project & $\begin{array}{c}\text { Exam \& } \\
\text { Assignment } \\
\text { Points } \\
\end{array}$ & $\begin{array}{c}\text { Entering } \\
\text { GPA }\end{array}$ & $\begin{array}{l}\text { Credit } \\
\text { Hours }\end{array}$ \\
\hline Night Student & 1.000 & & & & & & \\
\hline Integrity & -0.358 & 1.000 & & & & & \\
\hline Final Exam & -0.471 & 0.720 & 1.000 & & & & \\
\hline Final Project & 0.069 & 0.678 & 0.512 & 1.000 & & & \\
\hline Exam and Assignment Points & -0.411 & 0.767 & 0.988 & 0.636 & 1.000 & & \\
\hline Entering GPA & -0.205 & 0.498 & 0.660 & 0.380 & 0.660 & 1.000 & \\
\hline Credit Hours & -0.345 & 0.153 & 0.182 & -0.120 & 0.142 & 0.239 & 1.000 \\
\hline
\end{tabular}

Results from a regression analysis for each individual class show that integrity has a significant impact on student performance even after controlling for a student's incoming GPA. As can be seen in both Panel A and B of Exhibit 3, the coefficients on the "Integrity" variable are both positive and significant at the 0.01 level, even in the presence of positive and significant coefficients relating course performance to incoming GPA. Practicing integrity clearly adds value to the student's learning outcome regardless of the student's GPA. 


\begin{tabular}{|c|c|c|c|c|c|c|c|c|}
\hline \multicolumn{9}{|c|}{ Exhibit 3} \\
\hline \multicolumn{9}{|c|}{ Results of Regression of Exam and Assignment Points on Integrity Score and Entering GPA } \\
\hline \multicolumn{9}{|c|}{ Panel A: Finance 332 Spring 2011 Night Students } \\
\hline \multicolumn{2}{|c|}{ Regression Statistics } & & & & & & & \\
\hline Multiple R & 0.779 & & & & & & & \\
\hline R Square & 0.606 & & & & & & & \\
\hline Adjusted R Square & 0.578 & & & & & & & \\
\hline Standard Error & 18.835 & & & & & & & \\
\hline Observations & 31 & & & & & & & \\
\hline \multicolumn{9}{|l|}{ ANOVA } \\
\hline & $d f$ & SS & $M S$ & $F$ & Significance F & & & \\
\hline Regression & 2 & 15285.449 & 7642.724 & 21.544 & 0.000 & & & \\
\hline Residual & 28 & 9932.898 & 354.746 & & & & & \\
\hline \multirow[t]{2}{*}{ Total } & 30 & 25218.347 & & & & & & \\
\hline & Coefficients & Standard Error & tStat & $P$-value & Lower 95\% & Upper 95\% & Lower $95.0 \%$ & Upper $95.0 \%$ \\
\hline Intercept & -40.275 & 17.667 & -2.280 & 0.030 & -76.464 & -4.085 & -76.464 & -4.085 \\
\hline Integrity & 2.788 & 0.662 & 4.212 & 0.000 & 1.432 & 4.144 & 1.432 & 4.144 \\
\hline Beg GPA & 16.497 & 6.312 & 2.614 & 0.014 & 3.568 & 29.427 & 3.568 & 29.427 \\
\hline
\end{tabular}

\begin{tabular}{|c|c|c|c|c|c|c|c|c|}
\hline \multicolumn{9}{|c|}{ Panel B: Finance 332 Fall 2011 Day Students } \\
\hline \multicolumn{2}{|c|}{ Regression Statistics } & & & & & & & \\
\hline Multiple R & 0.913 & & & & & & & \\
\hline R Square & 0.834 & & & & & & & \\
\hline Adjusted R Square & 0.816 & & & & & & & \\
\hline Standard Error & 7.734 & & & & & & & \\
\hline Observations & 22 & & & & & & & \\
\hline \multicolumn{9}{|l|}{ ANOVA } \\
\hline & $d f$ & $S S$ & $\overline{M S}$ & $F$ & Significance F & & & \\
\hline Regression & 2 & 5690.40 & 2845.20 & 47.57 & $\overline{0.00}$ & & & \\
\hline Residual & 19 & 1136.38 & 59.81 & & & & & \\
\hline \multirow[t]{2}{*}{ Total } & 21 & 6826.78 & & & & & & \\
\hline & Coefficients & Standard Error & tStat & $P$-value & Lower 95\% & Upper 95\% & Lower $95.0 \%$ & Upper 95.0\% \\
\hline Intercept & -25.627 & 11.328 & -2.262 & 0.036 & -49.337 & -1.918 & -49.337 & -1.918 \\
\hline Integrity & 2.009 & 0.424 & 4.742 & 0.000 & 1.122 & 2.896 & 1.122 & 2.896 \\
\hline Beg GPA & 19.232 & 3.846 & 5.000 & 0.000 & 11.181 & 27.282 & 11.181 & 27.282 \\
\hline
\end{tabular}

A second regression analysis was conducted using the combined sample of students from both classes. To control for differences between the day and night students, an interaction variable was added to the analysis. The interaction variable was measured by multiplying the dummy variable "night student" (=1 if night student, 0 if day student), by the number of credit hours enrolled during the semester (based on prior findings that it is the total workload more than the fact that a student attends school at night that influences performance in the class).

As can be seen in Exhibit 4, the coefficient on integrity as a predictor of student performance outcome in this class is again positive and significant at the 0.01 level. As in the regressions for each separate class, the coefficient on incoming GPA is also positive and significant at the 0.01 level. The interaction term, 
measuring course workload for evening students, is negative and significant at the 0.05 level, indicating that there is a significant difference in performance of night students enrolled in a greater number of credit hours. Once again, however, it can be seen that ontological integrity adds value to a student's performance in the classroom.

\begin{tabular}{|c|c|c|c|c|c|c|c|c|}
\hline \multicolumn{9}{|c|}{ Exhibit 4} \\
\hline \multicolumn{9}{|c|}{$\begin{array}{l}\text { Regression Results: Total Exam and Assignment Points on Entering GPA, Integrity, and Night/Workload Status; Total } \\
\text { Sample }\end{array}$} \\
\hline \multicolumn{2}{|c|}{ Regression Statistics } & & & & & & & \\
\hline Multiple R & 0.845 & & & & & & & \\
\hline R Square & 0.713 & & & & & & & \\
\hline Adjusted R Square & 0.696 & & & & & & & \\
\hline Standard Error & 15.019 & & & & & & & \\
\hline Observations & 53 & & & & & & & \\
\hline \multicolumn{9}{|l|}{ ANOVA } \\
\hline & $d f$ & $S S$ & $M S$ & $F$ & Significance F & & & \\
\hline$\overline{\text { Regression }}$ & 3 & 27501.22 & 9167.07 & 40.64 & $\overline{0.00}$ & & & \\
\hline Residual & 49 & 11052.47 & 225.56 & & & & & \\
\hline \multirow[t]{2}{*}{ Total } & 52 & 38553.69 & & & & & & \\
\hline & Coefficients & Standard Error & $t$ Stat & $P$-value & Lower 95\% & Upper 95\% & Lower $95.0 \%$ & Upper $95.0 \%$ \\
\hline Intercept & -31.18 & 12.54 & -2.49 & 0.02 & -56.38 & -5.98 & -56.38 & -5.98 \\
\hline Beg GPA & 17.62 & 4.17 & 4.23 & 0.00 & 9.24 & 26.00 & 9.24 & 26.00 \\
\hline Integrity & 2.53 & 0.45 & 5.68 & 0.00 & 1.63 & 3.42 & 1.63 & 3.42 \\
\hline Night $*$ Credit Hours & -0.64 & 0.33 & -1.97 & 0.05 & -1.30 & 0.01 & -1.30 & 0.01 \\
\hline
\end{tabular}

\section{A Second Test Controlling for the Impact of Student Personality on the Results}

One potential criticism of the aforementioned results is that a student's integrity score is merely a proxy for certain personality characteristics such as obedience or general conscientiousness, and that introducing the students to a formal model of integrity will have no impact on their performance once this factor is accounted for. A second analysis, therefore, was conducted in a class of 35 graduate students at the Thunderbird School of Business in Phoenix, Arizona.

The structure of the course assignments and grading were similar between the two classes with the exception that all graded assignments were counted in the determination of the final grade calculation. Otherwise, the students were provided with the same orientation to the ontological model of integrity and graded on their performance in that component of the course.

It could be argued that integrity is not related to performance, but rather it captures some aspect of other dispositional traits. To better understand whether performance was influenced by integrity or dispositional attributes, we controlled for core self-evaluations (CSE). CSEs are a higher order construct, consisting of selfesteem, generalized self-efficacy, locus of control and emotional stability, and measure the general positive self-concept an individual has of him or herself. Selfesteem refers to the basic fundamental appraisal people make of themselves. 
Generalized self-efficacy refers to an individual's estimate of their capabilities to fulfill on tasks related to their life. Locus of Control refers to the extent to which individuals can control the events in their life. Emotional stability is a fundamental and stable personality trait that refers to the extent to which individuals experience negative emotional states. All four of these traits have been found to be stable over and individual's life and across cultures.

Core self-evaluations have been meta-analytically found correlate positively with performance ${ }^{3}$. Further, these four traits share a strong correlation and have been found to explain additional variance on performance, which suggests the use of a higher order construct. Similar to many studies before, we used a previously validated measure of CSEs, which has been developed and tested by which have been found to have a strong measure of reliability $(\alpha=.88)$, construct validity, and predictive validity.

To complete the CSE process, students filled out a survey that assessed these stable traits. The survey was completed at the beginning of class and before the concept of ontological integrity had been introduced. We then controlled for these traits, while assessing the other outcomes.

The results of the analysis confirm the significance of the impact on integrity and student learning outcomes. As can be seen in Exhibit 5, the regression coefficient on the integrity variable is still positive and significant at the 0.01 levels, even after accounting for incoming GPA, the student's GMAT score, and the students CSE personality assessment score. As in the prior analysis, the student's incoming GPA appears to be positively related to class performance in a significant manner. Neither the GMAT nor CSE variables appear to significantly affect the course grade score, after controlling for prior GPA and integrity. 


\begin{tabular}{|c|c|c|c|c|c|}
\hline \multicolumn{6}{|c|}{ Exhibit 5} \\
\hline \multicolumn{6}{|c|}{$\begin{array}{l}\text { Regression of Course Grade Score on Integrity, Incoming GPA, GMAT Score, } \\
\text { and CSE Personality Assessment for Graduate Students at Thunderbird } \\
\text { School of Business }\end{array}$} \\
\hline \multicolumn{2}{|c|}{ Regression Statistics } & & & & \\
\hline Multiple R & 0.848 & & & & \\
\hline R Square & 0.719 & & & & \\
\hline Adjusted R Square & 0.683 & & & & \\
\hline Standard Error & 3.814 & & & & \\
\hline Observations & 35 & & & & \\
\hline \multicolumn{6}{|l|}{ ANOVA } \\
\hline & $d f$ & $S S$ & $M S$ & $F$ & Significance $F$ \\
\hline Regression & 4 & 1155.029 & 288.757 & 19.854 & 0.000 \\
\hline Residual & 31 & 450.860 & 14.544 & & \\
\hline \multirow[t]{2}{*}{ Total } & 35 & 1605.889 & & & \\
\hline & Coefficients & Standard Error & t Stat & $P$-value & \\
\hline Intercept & 37.971 & 7.686 & 4.94 & 0.000 & \\
\hline Integrity & 3.584 & 1.359 & 2.637 & 0.013 & \\
\hline Beg GPA & 13.271 & 2.083 & 6.370 & 0.000 & \\
\hline GMAT & -0.002 & 0.01 & -0.194 & 0.847 & \\
\hline CSE & 1.271 & 1.25 & 1.017 & 0.317 & \\
\hline
\end{tabular}

The Thunderbird findings confirm the other findings that the practice of ontological integrity improves classroom workability and enhances student performance outcomes even after accounting for factors such as incoming GPA and a student's personality traits. In all cases, acting with integrity adds value to performance.

What is most striking about this result is that we see how integrity improves course performance regardless of the level of that student's prior overall academic performance. The fact that this type of integrity can be taught and learned demonstrates that it is possible to improve workability in a variety of other situations merely by teaching and practicing this form of ontological integrity.

\section{Broader Applicability of the Integrity Model to Other Performance Environments}

Part of the motivation for this study was to test whether the application of a positive model of integrity based on a definition of one's word would improve workability in a functional environment. In this case, participants were giving their word to meeting the conditions necessary to fulfill the promise of a course, where the course experience provided the functional environment. The study results show 
that in cases where participants honor their word, workability, and hence, performance, are enhanced.

This model is also applicable to a broader variety of work environments, including those in which acknowledged ethical standards are important. As shown earlier, part of one's word includes the following:

Moral, Ethical And Legal Standards: The social moral standards, the group ethical standards and the governmental legal standards of right and wrong, good and bad behavior, in the society, groups and state in which one enjoys the benefits of membership are also part of one's word (what one is expected to do) unless a) one has explicitly and publicly expressed an intention to not keep one or more of these standards, and b) one is willing to bear the costs of refusing to conform to these standards (the rules of the game one is in).

Provided that there is a clear articulation and understanding of moral, ethical and legal standards, the act of honoring one's word would call for either assumed adherence or vocal objection to those standards. As those engaged in working relationships in this environment choose to honor their word, the ethical standard of behavior would become more consistent and overall workability would be improved as a result. Further implementation and study of this model will enable validation of its broader applicability. 


\section{Appendix 1}

Fin 332: Integrity Grading Rubric; Steven C. Isberg, Instructor; Fall 2010

\begin{tabular}{|c|c|c|c|c|}
\hline Component & Exceds Standard & Meets Standard & Below standard & Points \\
\hline $\begin{array}{l}\text { Class attendance (0-5 } \\
\text { points) }\end{array}$ & $\begin{array}{l}\text { Student attends all class } \\
\text { sessions }\end{array}$ & $\begin{array}{l}\text { Student does not } \\
\text { attend all class } \\
\text { sessions, however; as } \\
\text { soon as student } \\
\text { realizes that class will } \\
\text { be missed, student } \\
\text { informs the instructor } \\
\text { and provides a plan for } \\
\text { making up any missed } \\
\text { work or responsibilities }\end{array}$ & $\begin{array}{l}\text { Student misses class or } \\
\text { classes and does not } \\
\text { inform instructor of } \\
\text { absences and/or provide } \\
\text { a plan for making up any } \\
\text { missed work or } \\
\text { responsibilities on a } \\
\text { timely basis }\end{array}$ & \\
\hline $\begin{array}{l}\text { Assignment Submission } \\
\text { (0-10 points) }\end{array}$ & $\begin{array}{l}\text { Student submits each } \\
\text { assignment on time and in } \\
\text { proper format }\end{array}$ & $\begin{array}{l}\text { As soon as student } \\
\text { realizes that s/he will } \\
\text { not submit an } \\
\text { assignment on time, } \\
\text { s/he lets the professor } \\
\text { know and provides a } \\
\text { plan for making up any } \\
\text { deficiencies resulting } \\
\text { from the late } \\
\text { submission }\end{array}$ & $\begin{array}{l}\text { Student fails to submit } \\
\text { assignments on time and } \\
\text { makes no timely effort } \\
\text { to inform the instructor } \\
\text { or make up for any } \\
\text { deficiencies that result }\end{array}$ & \\
\hline Self-tests (0-5 points) & $\begin{array}{l}\text { Student completes and } \\
\text { submits all self-tests on } \\
\text { time }\end{array}$ & $\begin{array}{l}\text { Student informs the } \\
\text { instructor as soon as } \\
\text { s/he is aware that a } \\
\text { self-test will not be } \\
\text { submitted on time, } \\
\text { and provides a plan for } \\
\text { making up any } \\
\text { resulting deficiencies }\end{array}$ & $\begin{array}{l}\text { Student fails to submit } \\
\text { self tests on time and } \\
\text { makes no timely effort } \\
\text { to make up for any } \\
\text { resulting deficiencies }\end{array}$ & \\
\hline $\begin{array}{l}\text { Seeking assistance (0-5 } \\
\text { points) }\end{array}$ & $\begin{array}{l}\text { Student responds to } \\
\text { professor's invitation or } \\
\text { suggestion or initiates } \\
\text { process of seeking } \\
\text { assistance on his/her } \\
\text { own. }\end{array}$ & $\begin{array}{l}\text { If student falls behind } \\
\text { in seeking assistance, } \\
\text { student informs the } \\
\text { instructor as soon as } \\
\text { possible and submits a } \\
\text { plan for making up any } \\
\text { resulting deficiencies }\end{array}$ & $\begin{array}{l}\text { Student fails to respond } \\
\text { to professor's invitation } \\
\text { or suggestion and/or } \\
\text { does not seek assistance } \\
\text { when needed. }\end{array}$ & \\
\hline Total & 25 & $17-24$ & $<17$ & \\
\hline
\end{tabular}




\section{Bibliography}

Erhard, Werner H.; Michael C. Jensen, and Steve Zaffron; Integrity: A Positive Model That Incorporates The Normative Phenomena of Morality, Ethics, and Legality Abridged; Harvard Business School NOM Working Paper No. 10-061, Barbados Group Working Paper No. 10-01; Simon School of Business Working Paper No. 1007, 7 March 2010

Erhard, Werner H.; Michael C. Jensen, Steve Zaffron, and Kari Granger; Being a Leader and the Effective Exercise of Leadership: An Ontological Model; Course Material, 2010

Judge, Tim A.; Edwin A. Locke; Cathy C. Durham; The dispositional causes of job satisfaction: A core evaluations approach; Research in Organizational Behavior 19: 151-188, 1997. 